\title{
SPECIATION OF METALS IN THE FINE FRACION OF SOLID WASTE FROM AN EXCAVATED LANDFILL Fabio Kaczala ${ }^{1}$ Kaja Orupõld ${ }^{2}$ Anna Augustsson ${ }^{1}$ William Hogland ${ }^{1}$ \\ ${ }^{1}$ Linnaeus University, Sweden \\ ${ }^{2}$ Estonian University of Life Science, Estonia
}

\begin{abstract}
In this current study, speciation of metals in the fine fraction $(<10 \mathrm{~mm})$ of excavated solid waste from an Estonian landfill was performed in order to evaluate metal contents and their potential mobility and bioavailability. The fine fraction speciation was carried out following the $\mathrm{BCR}$ sequential extraction method for $\mathrm{Pb}, \mathrm{Cu}$ and $\mathrm{Cd}$ and the exchangeable $(\mathrm{F} 1)$, reducible $(\mathrm{F} 2)$, oxidizable $(\mathrm{F} 3)$ and residual $(\mathrm{F} 4)$ fractions were determined. The results have shown that $\mathrm{Pb}$ was highly associated with the reducible (F2) and oxidizable (F3) fractions suggesting the potential mobility of such metal mainly when in contact with oxygen, despite the low association with the exchangeable fraction (F1). The metal $\mathrm{Cu}$ has shown also potential for mobility and bioavailabilty when in contact with oxygen since high associations with the oxidizable fraction (F3). On the other hand, Cd was mostly found associated with the residual fraction (F4) were observed raising low concerns regarding mobility and toxic effects in case of excavation. To conclude, studies addressed to understand not only the total concentration of metals in solid phase, but also the speciation and which form metals are bound, are very important in order to bring information on how to manage fine fraction from excavated waste both in terms of environmental impacts and also recovery/extraction.
\end{abstract}

\section{KEYWORDS}

Landfill mining; Fine fraction; heavy metals; metals speciation, mobility, bioavailability, toxicity

https://doi.org/10.15626/Eco-Tech.2014.011 


\section{INTRODUCTION}

Whereas significant amounts of important natural resources have been discarded as urban and industrial waste, an increase in global consumption and the consequent depletion of natural stocks (including metals) and higher market prices have been highlighted. Population growth and the need to supply all inhabitants with commodities bring the necessity to shift the traditional linear models followed by our society not only into closed-loop models but also consider the recovery of all valuable resources we have lost as waste products from our daily activities. Landfilling has been one of the most dominant ways of solid waste disposal in many parts of the world (Laner et al., 2012). However, at the same time that landfills pose enormous risks to human health and the environment, landfills can also be viewed as a secondary source of materials (plastics, glass and metals) and energy (direct collection of methane or energy recovery through incineration of materials with high calorific values such as plastics). Therefore, there is a new trend to consider landfills as "alternative mines", even though research in this area is still in the emerging phase (Krook, 2010). Landfill mining refers to the extraction, processing, treatment and/or recovery of deposited material and the concept was established in Israel in 1953 even though the interests in landfill mining were observed from the 1990's (Frändegård et al. 2012). Despite the report of a number of landfill mining projects, only few of them were focused on resource recovery being most of them addressed for solving local concerns of landfill space, urban expansion, environmental protection and remediation of local pollution (Frändegård et al. 2012). It has been reported that one essential finding of previous waste characterization of landfilled waste is the presence of fine fractions $(<18 \mathrm{~mm})$, which can contribute to more than $50 \%$ of the total mass of an excavated landfill. (Kaartinen et al. 2013). However, even though the fine fraction is an important contributor to the total mass of an excavated landfill, the composition of fine fraction and also the potential environmental and ecological disturbances are rarely studied and reported in the literature. Therefore, in this current study, speciation of metals in the fine fraction $(<10 \mathrm{~mm})$ of excavated solid waste from an Estonian landfill was performed in order to evaluate metal contents and their potential mobility and bioavailability. The fine fraction speciation was carried out following the BCR sequential extraction method for $\mathrm{Pb}, \mathrm{Cu}$ and $\mathrm{Cd}$ and the exchangeable (F1), reducible (F2), oxidizable (F3) and residual (F4) fractions were determined.

\section{MATERIALS AND METHODS}

\subsection{Description of the landfill site and sampling procedures}

The fine fraction $(<10 \mathrm{~mm})$ was obtained from landfill mining activities that took place at Kudjape Landfill, located in the Island of Saaremaa (N 58:16:06, E 22:32:23), $2 \mathrm{~km}$ southeast from Kuressaare town, Estonia during February 2013. The sampling at Kudjape Landfill was done four test pits $\left(T P_{1}, T P_{2}, T P_{3}, T P_{4}\right)$, which were then divided in four sampling depths $\left(L_{1}, L_{2}, L_{3}, L_{4}\right)$. Each test pit had a total excavation depth of approximately $5 \mathrm{~m}$ including the $30-50 \mathrm{~cm}$ topsoil cover layer that was previously removed; thus, each layer had an approximate depth of $1 \mathrm{~m}$, and sample volume of $1 \mathrm{~m}^{3}$. An example of one test pit and respective sampling layers is illustrated in Figure 1. 
As soon as $1 \mathrm{~m}^{3}$ of waste was excavated from each layer within a specific test pit, the waste was fed into a trommel screen Doppstadt SM518 for an initial separation of the waste in two fractions: 1) $>40 \mathrm{~mm}$ and 2) $<40 \mathrm{~mm}$. The fraction $<40 \mathrm{~mm}$ was further screened down to $<10 \mathrm{~mm}$ which was the fraction (fine-grained fraction) used in this study. Considering four test pits with samples taken in four different layers, a total of 16 samples of fine fraction, approximately $10 \mathrm{~L}$ each, were transported to the laboratory and stored under $4^{\circ} \mathrm{C}$ until the leaching tests were performed.

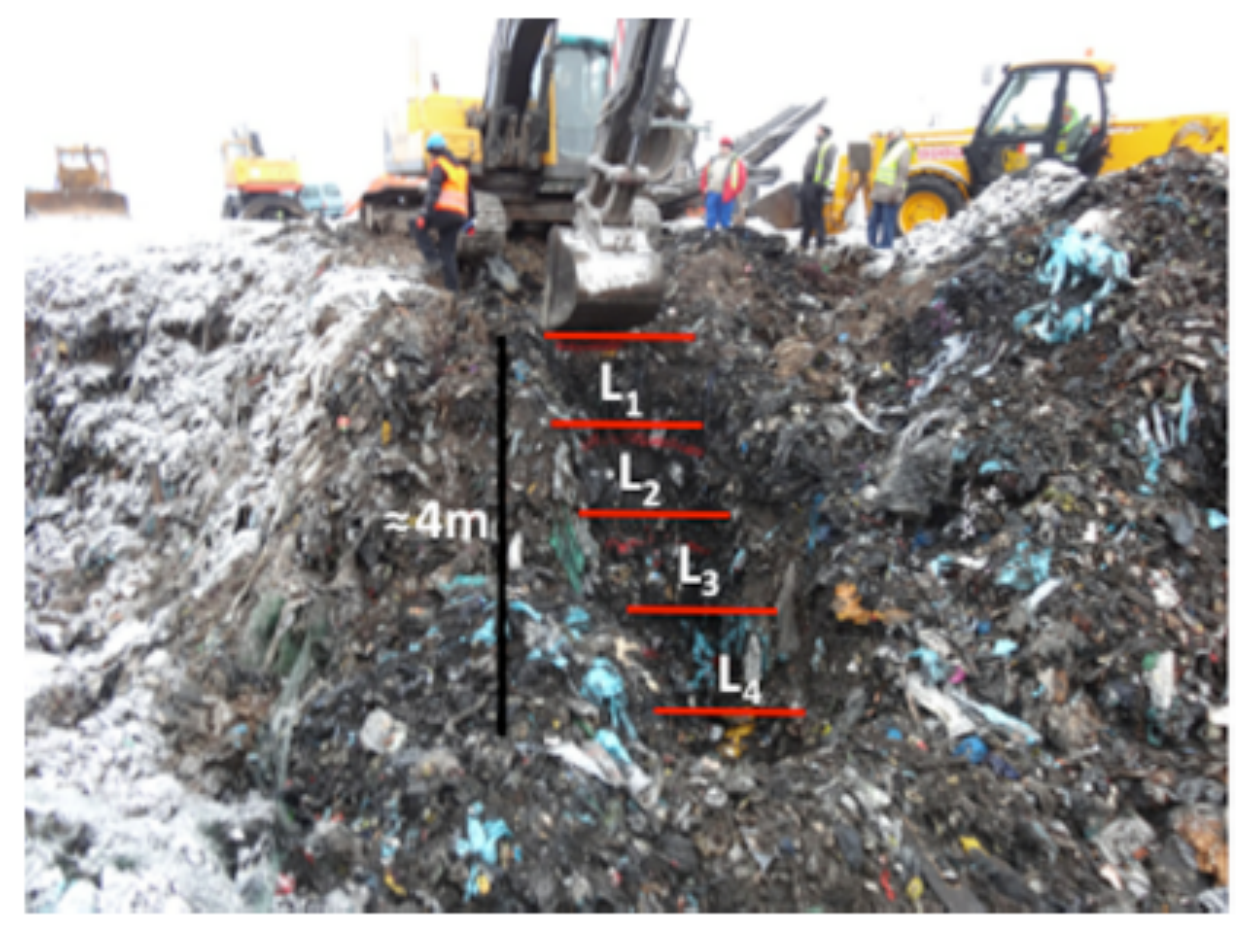

Figure 1: Excavation of test pit $1\left(T P_{1}\right)$ with excavation layers indicated in red lines

\subsection{Sample preparation for sequential extraction}

Leaching tests were done with eight composite sub-samples obtained from the 16 original ones (four test pits with four different layers each) in order to evaluate the spatial variability and the influence of waste age on leaching properties. Composite sub-samples from the test pits $\left(\underline{T P_{x}}\right)$ and the different sampling layers $\left(L_{x}\right)$ were obtained as follows (Eq. 1 and 2):

$$
\begin{array}{ll}
T P_{X}=L_{1 X}+L_{2 X}+L_{3 X}+L_{4 X} & \text { Eq. } 1 \\
L_{X}=T P_{1 X}+T P_{2 X}+T P_{3 X}+T P_{4 X} & \text { Eq. } 2
\end{array}
$$

Where $X$ is the number of the test pit ( 1 to 4 ) and the layers ( 1 to 4 ) respectively. 


\subsection{Sequential extraction procedure (SEP)}

The sequential extraction was carried out according to the BCR three-step procedure that determines four well defined geochemical fractions of metals in sediments: acidsoluble/exchangeable fraction (F1), reducible fraction (F2), oxidizable fraction (F3) and residual fraction (F4). Prior to the extraction procedures, all tubes and glassware were soaked in diluted nitric acid $(10 \% \mathrm{v} / \mathrm{v})$ for $8 \mathrm{~h}$ and rinsed with ultra pure water produced by a Milli-Q $\mathrm{Q}^{\mathrm{TM}}$ apparatus (Millipore, $18.2 \mathrm{M} \Omega / \mathrm{cm}$ resistivity). A detailed description of fractionation procedures is given as follows:

Step 1 (acid extractable/exchange fraction - bound to carbonates)

The first fraction of metals was extracted by accurately weighing $0.5 \mathrm{~g}$ of dry sediments, placing them in polyethylene centrifuge tubes followed by the addition of $20 \mathrm{~mL}$ of 0.11 M acetic acid (100\%, Scharlau Chemie S.A, Barcelona, Spain) and mechanically shaken (270 rpm) on an end-over-end shaker (Rotamix RM1) for $16 \mathrm{~h}$ at room temperature (approx. $23 \pm 2{ }^{\circ} \mathrm{C}$ ). The extracts were then separated from the residue by centrifugation for $20 \mathrm{~min}$ at $3000 \mathrm{rpm}$, rinsed with distilled water, hand shaken, decanted and finally stored in acid-rinsed polypropylene tubes for further analysis. To continue in Step 2, residual sediments were washed with $20 \mathrm{~mL}$ distilled water, shaken for $15 \mathrm{~min}$ (Rotamix RM1) and centrifuged at $3000 \mathrm{rpm}$. In a sequence, decantation of supernatant was carried out to eliminate any remaining particles before the next extraction step.

Step 2 (reducible fraction - bound to Fe/Mn oxides)

After $\mathrm{pH}$ adjustment to 1.5 with $2 \mathrm{~mol} / \mathrm{L}$ nitric acid $(65 \%$, Scharlau Chemie S.A, Barcelona, Spain), $20 \mathrm{~mL}$ of fresh hydroxyl ammonium chloride $0.5 \mathrm{M}$ (Scharlau Chemie S.A, Barcelona, Spain) was added to the residual sediments of Step 1 and shaken (270 $\mathrm{rpm}$ ) for $16 \mathrm{~h}$ at room temperature. The extraction was performed as previously described in Step 1.

Step 3 (oxidizable fraction - bound to organic matters and sulfides)

Initially, $5 \mathrm{~mL}$ of hydrogen peroxide $8.8 \mathrm{M}(30 \%$, Scharlau Chemie S.A, Barcelona, Spain) adjusted to $\mathrm{pH}$ 2-3 was carefully added to the remaining sediments of Step 2 in a $50-\mathrm{mL}$ centrifuge tube followed by a two-step digestion: first digestion at room temperature (approx. $23 \pm 2{ }^{\circ} \mathrm{C}$ ) for $1 \mathrm{~h}$ and a second digestion for additional $1 \mathrm{~h}$ at $85 \pm$ $2{ }^{\circ} \mathrm{C}$ in a water bath. Following the digestion step, a second addition of $5 \mathrm{~mL} \mathrm{pH}$-adjusted hydrogen peroxide was carried out; the centrifuge tube was then covered and heated at $85 \pm 2{ }^{\circ} \mathrm{C}$ until it reached an approximate final volume of $2-3 \mathrm{~mL}$. Samples were then removed from the water bath, cooled down to approximately $23 \pm 2{ }^{\circ} \mathrm{C}$ followed by addition of $25 \mathrm{~mL}$ of $1.0 \mathrm{M}$ ammonium acetate (Fisher Scientific, Loughborough, Leicestershire, UK) and shake for $16 \mathrm{~h}$. The extraction was performed as previously described in Step 1.

Step 4 (residual fraction - strongly associated to the crystalline structures of the minerals)

The residue from the last step was digested with a mixture of aqua regia (nitric acid: hydrochloric acid in 1:3) and hydrofluoric acid (40\%, Scharlau Chemie S.A, Barcelona, Spain) consisting of $5 \mathrm{~mL}$ nitric acid $+15 \mathrm{~mL}$ hydrochloric acid $+2 \mathrm{~mL}$ hydrofluoric acid. Hydrochloric acid was of analytical grade (36\% Fisher Scientific, Loughborough, Leicestershire, UK).

\subsection{Total digestion}


The samples used for total digestion were air dried, hence avoiding volatile compounds to be lost during heating. $4.0 \mathrm{~g}$ of dried material from the $<2 \mathrm{~mm}$ fraction were then digested in $3.0 \mathrm{ml} \mathrm{HCl}$ and $3.0 \mathrm{ml} \mathrm{HNO} 3$ in a closed $50 \mathrm{ml}$ quartz vessel in a Perkin Elmer Microwave oven. The oven was run according to a three-step program. In the first step, the power was set to $400 \mathrm{~W}$ during 6:00 minutes and a fan speed of 1 was chosen. The second step had an effect of $900 \mathrm{~W}$ for 9:00 minutes and a fan speed of 1. Finally a cooling phase was run during 15:00 min, with a fan speed of 3. The digested samples were transferred into $50-\mathrm{ml}$ volumetric flasks and diluted with $18.2 \mathrm{M} \Omega / \mathrm{cm}^{2}$ Milli- $\mathrm{Q}^{\mathrm{TM}}$ water

\subsection{Analytical procedures}

The metals $\mathrm{Zn}, \mathrm{Cu}, \mathrm{Pb}$ and $\mathrm{Cd}$ in leachates were analyzed after filtration through $0,45 \mu \mathrm{m}$ filters attached to $50 \mathrm{ml}$ syringes by atomic absorption spectroscopy - AAS (Model Analyst 4). Analysis of $\mathrm{Cd}$ was performed using atomic absorption spectrophotometer (AA-6800, Shimadzu) equipped with graphite furnace atomizer (GFA-EX7).

\section{RESULTS AND DISCUSSION}

\subsection{Distribution of metals in the fine fraction}

Despite the use of total metal concentrations as an indicator of potential ecological risks, an assessment of the different geochemical forms of metals in different types of sediments brings a better understanding of mobility and bioavailability (Gao and Chen 2012). However, on the other hand, there is no study in the literature in relation to speciation of metals in fine-grained fraction of waste excavated from landfills, which makes it very difficult to compare the results of the current investigation. This study is one of the first, if not the first one to focus on the four different fractions of excavated waste under $<10 \mathrm{~mm}$. The first step of sequential extraction obtains the extractable/exchangeable fraction (F1) of metals that are weakly associated to carbonates and can be released by the action of cations such as $\mathrm{K}, \mathrm{Ca}, \mathrm{Mg}$, or (NH4) that displace metals weakly associated with organic and inorganic sites (Beckett 1989). The high mobility, bioavailability, and potential toxicity/bioaccumulation of exchangeable metals in aquatic organisms are of great concern and changes in salinity and $\mathrm{pH}$ increase have been reported to increase metal mobility in aquatic ecosystems (Chen et al. 2010) but no study has been found in relation to landfilled waste. According to the Figure 2 little association of studied metals with the mobile fraction was found which gives a preliminarily positive status in terms of mobility and availability. The metal that has shown the highest association \% with the mobile fraction was Pb in TP3 and TP4 with $13 \%$ and $10 \%$ respectively. However even though low association of $\mathrm{Pb}$ with mobile fraction was observed changes in environmental conditions could modify this scenario and potential ecological risks would still exist. The second fraction of extracted metals, the reducible fraction (F2), indicates the metals that are usually associated with $\mathrm{Fe}$ and $\mathrm{Mn}$ oxy/hydroxides and associations of $\mathrm{Pb}$ with $\mathrm{F} 2$ ranging between $16 \%-35 \%$ and 33\%$50 \%$ respectively were observed highlighting as previously mentioned that even though low $\%$ of associations of $\mathrm{Pb}$ with $\mathrm{F} 1$ were observed, environmental and ecological risks cannot be ruled out since metals in the reducible phase are still labile and might be released to the environment upon decomposition of the oxides under sub-oxic conditions 
(Delgado et al. 2011) and redox changes (Chen et al. 2010). The metals bound to organic matter and sulfides (F3) are extracted during the third step of the sequential fractionation (oxidizable fraction). Under oxidizing conditions, organic matter degradation can lead to a release of metals bound to this fraction. The organic fraction released during the extraction is not bioavailable due to its association with stable humic substances that release small amounts of metals slowly (Filgueiras et al. 2002). The results have shown that $\mathrm{Cu}$ was the metal with high \% of association with the oxidizable fraction as observed in the Figure 2. The association of $\mathrm{Cu}$ with the oxidizable fraction ranged between $63 \%$ and $83 \%$. It is important to highlight that despite the possibilities of sulfides and organic matter oxidation during excavation and consequent redistribution of different fractions, such results are realistic considering the real scenario of landfill excavation in which sediments are taken up to the surface and oxygenation is likely to occur. It can be suggested that the potential risks posed by metals bound to organic matter (associated with F3) must be mainly considered in cases, which landfill mining activities are planned and fine fraction is left in open areas until a decision on final destination is done.
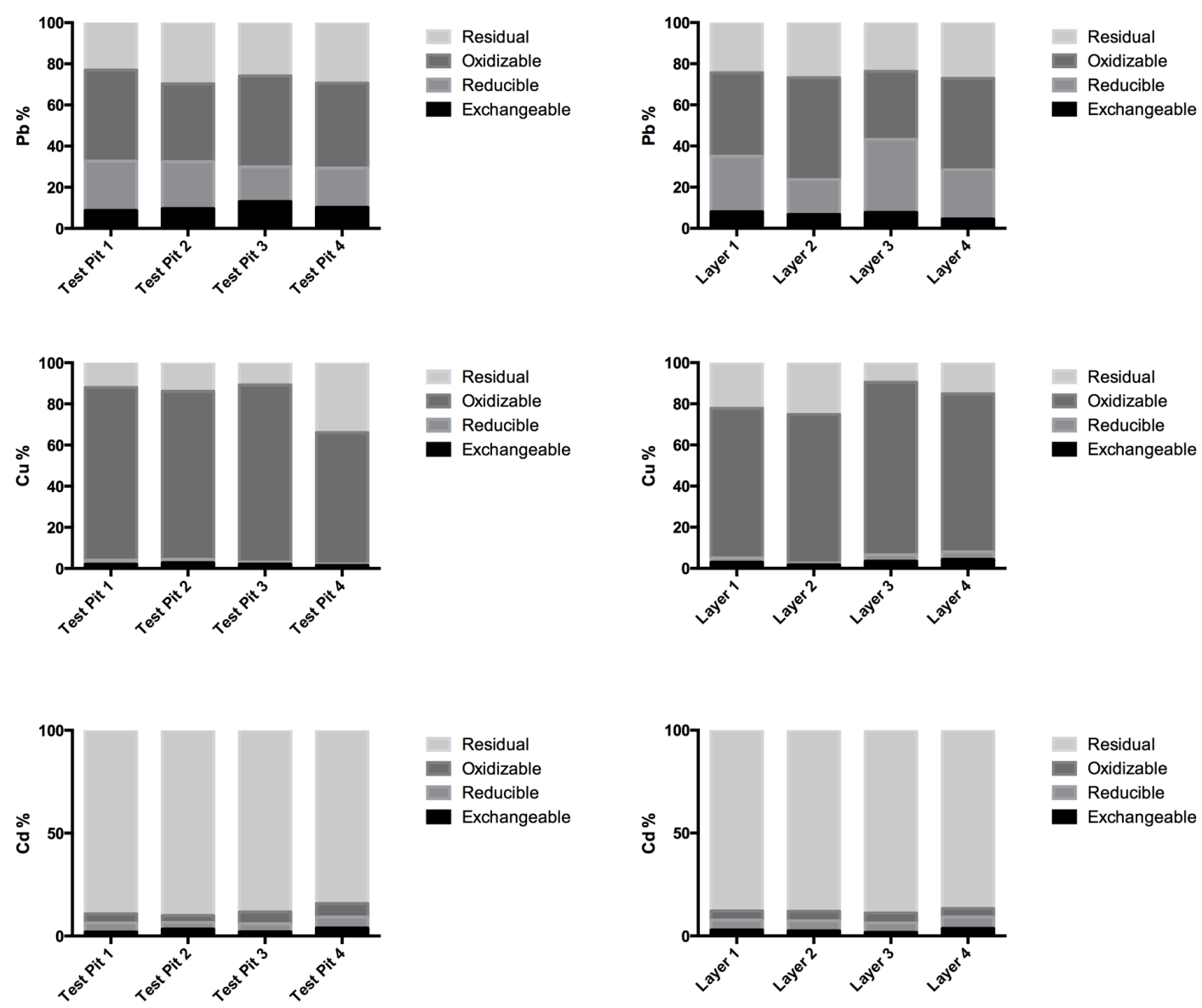

Figure 2: Distribution of element fractionation in the fine fraction excavated from Kudjape Landfill, Saarema, Estonia. 


\section{CONCLUSIONS}

In this current study, speciation of metals in the fine fraction $(<10 \mathrm{~mm})$ of excavated solid waste from an Estonian landfill was performed in order to evaluate metal contents and their potential mobility and bioavailability. The fine fraction speciation was carried out following the $\mathrm{BCR}$ sequential extraction method for $\mathrm{Pb}, \mathrm{Cu}$ and $\mathrm{Cd}$ and the exchangeable $(\mathrm{F} 1)$, reducible $(\mathrm{F} 2)$, oxidizable $(\mathrm{F} 3)$ and residual $(\mathrm{F} 4)$ fractions were determined. The results have shown that $\mathrm{Pb}$ was highly associated with the reducible (F2) and oxidizable (F3) fractions suggesting the potential mobility of such metal mainly when in contact with oxygen, despite the low association with the exchangeable fraction (F1). The metal $\mathrm{Cu}$ has shown also potential for mobility and bioavailabilty when in contact with oxygen since high associations with the oxidizable fraction (F3). On the other hand, Cd was mostly found associated with the residual fraction (F4) were observed raising low concerns regarding mobility and toxic effects in case of excavation. To conclude, studies addressed to understand not only the total concentration of metals in solid phase, but also the speciation and which form metals are bound, are very important in order to bring information on how to manage fine fraction from excavated waste both in terms of environmental impacts and also recovery/extraction.

\section{ACKNOWLEDGEMENTS}

The authors would like to acknowledge the financial support from the Swedish Institute SI and the Environmental Investment Centre in Estonia. We are grateful for the help obtained during the excavation and field work from the MSc and Phd students of Kaunas University of Technology (Department of Environmental Technology), Estonian University of Life Sciences (Institute of Agricultural and Environmental Sciences and the Department of Water Management), University of Latvia (Faculty of Chemistry), Taras Shevchenko National University of Kyiv and Linnaeus University (Environmental Science and Engineering Group). The fieldwork would not be done without crucial help of Olavi and Rein-Erik from RTS-Infra Ltd. Many thanks go to the support given by Valdo Liv and Mihkel Paljak.

\section{REFERENCES}

Beckett PHT (1989) The Use of Extractants in Studies of Trace Metals in Soils, Sewage Sludges, and Sludge-treated soils. In: Stewater BA (Ed), Advances in Soil Science, Springer-Verlag, New York, pp 143-171.

Chen C, Lu J, Ye M, Wang Y, Lu H (2010) Metal and metalloid contaminant availability in Yundang Lagoon Sediments. Xiamen Bay, China, after 20 years continuous rehabilitation. J. Hazard. Mater 175: 1048-1055.

Delgado J, Barba-Brioso C, Nieto JM, Boski T (2011) Speciation and ecological risk of toxic elements in estuarine sediments affected by multiple anthropogenic contributions (Guadiana saltmarshes, SW Iberian Peninsula): I. Surficial sediments. Sci. Total Environ. 409: 3666-3679. 
Filgueiras AV, Lavilla I, Bendicho C (2002) Chemical sequential extraction for metal Partitioning in environmental solid samples. J of Environ Monit 4: 823-857.

Frändegård, P., Krook, J., Svensson, N., Eklund, M. (2013). A novel approach for environmental evaluation of landfill mining. Journal of Cleaner Production. 55-24:34

Gao X, Chen C-TA (2012) Heavy metal pollution status in surface sediments of the coastal Bohai Bay. Water Res 46:1901-1911.

Kaartinen, T., Sormunen, K., Rintala, J., 2013. Case study on sampling processing and characterization of landfilled municipal solid waste in the view of landfill mining. Journal of Cleaner Production. 55,56-66.

Laner, D., Crest, M., Scharff, H., Morris, J.W.F., Barlaz, M.A., 2012. A review of approaches for the long-term management of municipal solid waste landfills. Waste Management. 32,498-512.

Masi, S., Caniani, D., Grieco, E., Lioi, D.S., Mancini, I.M., 2014. Assessment of the possible reuse of MSW coming from a landfill mining of old open dumpsites. Waste Management. 34,702-710. 